\title{
Juvenile recurrent respiratory papillomatosis: 10 year audit and Australian prevalence estimates
}

*Daniel Novakovic, FRACS MBBS MPH BSC

Clinical Senior Lecturer, University of Sydney Medical School, the Canterbury Hospital, Suite 1. Level 1, 66 Pacific Highway St Leonards, Australia

Ph: 1300286423

Email: Daniel.novakovic@sydney.edu.au

Alan T.L. Cheng, MBChB, BHB, FRACS

Clinical Associate Professor, Department of Paediatric Otolaryngology, The Children's Hospital at Westmead, University of Sydney, Locked Bag 4001 Westmead NSW 2145, Australia

Suite 6a, Level 6, 9-13 Redmyre Road, PO Box 610, Strathfield NSW 2135

Katherine Baguley, MBChB, FRACS OHNS

ENT surgeon, Wellington Hospital, New Zealand

Paul Walker, MBBS FRACS FACS

Paediatric Otolaryngologist, Conjoint Associate Professor, Disciplines of Surgery and

Paediatrics,

University of Newcastle, PO Box 293, New Lambton NSW 2305

Henley Harrison, MB.BS.,FRCS(Eng),FRCS(Ed), FRACS.

Head, Ear, Nose and Throat Department, Sydney Children's Hospital, Randwick. 303/135 Macquarie Street, Sydney, 2000.

Marlene Soma, BSc(Med) MBBS FRACS

Paediatric Ear Nose and Throat Surgeon, Sydney Children's Hospital

High St, Randwick NSW 2031, Australia

Michael Malloy, B Math Stat Sci (Hons), PhD

National HPV Vaccination Program Register, East Melbourne, Victoria, Australia

Julia M. L. Brotherton, B Med (Hons), MPH (Hons), Grad Dip App Epi, FAFPHM, PhD. National HPV Vaccination Program Register, East Melbourne, Victoria, Australia Honorary Principal Fellow, School of Population and Global Health, University of Melbourne, Victoria, Australia

\section{*Corresponding author}

\section{Running title: RRP burden of disease in Australia}

Level of Evidence: Level 4 case series

\section{Conflict of interest:}

This is the author manuscript accepted for publication and has undergone full peer review but has not been through the copyediting, typesetting, pagination and proofreading process, which may lead to differences between this version and the Version record. Please cite this article as doi:10.1002/ lary.26005. 
JB has been an investigator on investigator designed unrestricted epidemiological research grants partially funded through bioCSL/Merck but has received no personal financial benefits.

\section{Financial Disclosures:}

Supported in part by a research grant from the Investigator Initiated Studies Program of

Merck. The opinions expressed in this paper are those of the authors and do not necessarily represent those of Merck Sharp \& Dohme Corp

Key words: RRP, human papillomavirus, HPV, immunization, papillomatosis, larynx

Objectives: To estimate the prevalence of juvenile onset Recurrent Respiratory

Papillomatosis (RRP) in Australia, describe its epidemiological profile and assess the positive predictive value of ICD-10 code D14.1 (benign neoplasm of larynx) in children for hospitalization due to RRP.

Study Design: Retrospective case series

Methods: Retrospective case review undertaken at the three tertiary paediatric hospitals in New South Wales (Australia's largest state), by reviewing medical records of patients aged 0-16 years admitted 2000 - 2009 containing the ICD-10AM (Australian modification) code D14.1 or other possible disease (D14.2-4, D14.3, D14.4) and RRP-related procedure codes.

For RRP diagnoses, we recorded treatment dates, length of stay, extent of disease, surgical and adjuvant treatments. The positive predictive value (PPV) of code D14.1 and median number of hospitalizations per year were applied to national hospital separations data $2000 / 2001$ to $2012 / 2013$ to estimate disease prevalence.

Results: We identified 30 cases of RRP using code D14.1, which had a PPV of $98.1 \%$, with no further cases identified using other codes. $57 \%$ of cases were female, median age of onset was 36 months and median treatment duration was 36 months (mean $=40$ months, range $=$

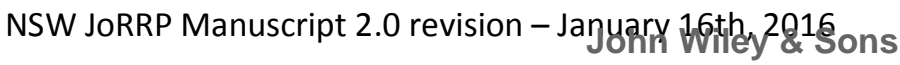

This article is protected by copyright. All rights reserved. 
1-118 months). There was one patient death. Between 2000-2013, the estimated national prevalence rate was 0.81 per 100,000 aged $<15$, peaking at age $5-9$ years $(1.1$ per 100,000$)$. Conclusion: RRP prevalence can be monitored post-HPV vaccination programs using routine hospital data.

\section{Introduction/Background}

Recurrent Respiratory Papillomatosis (RRP) can be associated with significant morbidity and impact upon quality of life in children ${ }^{1}$. The role of human papillomavirus (HPV), predominantly types 6 and $11^{2}$, as the cause of RRP has been recognised for over 30 years ${ }^{3-}$

${ }^{5}$. Juvenile onset RRP is thought to occur following vertical transmission of HPV before/during birth, with maternal history of genital warts a significant risk factor ${ }^{6-8}$. While exposure to HPV is probably common, only a small minority develop RRP. An immunologic

deficit expressed as the inability to clear or suppress HPV expression in the airways is postulated to explain the occurrence of $\mathrm{RRP}^{9}$.

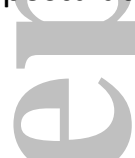

The rarity of the disease, and its variable course, has made studying the disease and the efficacy of potential treatment strategies challenging. Prevalence estimates range from $<1$ to 4 per $100,000^{10}$. Typically patients require multiple treatments over years to maintain airway and voice, although this is highly variable with most requiring less frequent surgery over time ${ }^{11,12}$.

Infection with HPV types 6 and 11 (and types 16 and 18, the most oncogenic types) is now preventable through vaccination. The quadrivalent HPV vaccine (Gardasil, Merck) prevents

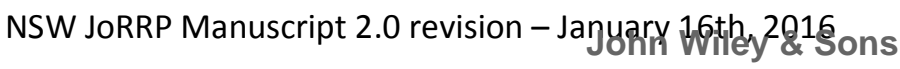

This article is protected by copyright. All rights reserved. 
infection and disease due to the four targeted types ${ }^{13}$. However, the vaccine trials indicate that vaccination does not treat existing infection or disease. Despite case reports and retrospective reviews temporally associating vaccination with disease remission, there is currently no randomised trial evidence that vaccination is useful therapeutically in RRP patients ${ }^{14-17}$. Rather, RRP may now be prevented via vaccination of females, therefore dramatically reducing the chance of infant exposure to HPV6/11. In Australia a quadrivalent vaccine program (for females aged 12 to 26 year) commenced in 2007 and achieved high coverage ${ }^{18,19}$. The incidence of genital warts rapidly declined, as did the prevalence in young women of vaccine targeted HPV types including HPV6 and $11^{20-22}$.

Measuring the impact of HPV vaccination programs on RRP is challenging due to disease rarity and lack of routine surveillance. We previously conducted a pilot retrospective audit of cases from one of three tertiary children's hospitals in the Australian state of New South Wales (NSW), ${ }^{23}$. We estimated a peak prevalence rate nationally of $1.2-1.8$ per 100,000 children aged 5-9 years. In the present study we include the two remaining tertiary children's hospitals in NSW and longer time period. We aimed to (1) describe the epidemiological profile of juvenile onset RRP in NSW between 2000-2009; and (2) by using national hospitalisation data, estimate the prevalence of juvenile onset RRP in Australia prior to and after the implementation of the National HPV Vaccination Program.

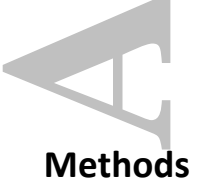

1) Retrospective case review

A retrospective case review was undertaken at the three tertiary paediatric hospitals in NSW - The Children's Hospital at Westmead, John Hunter Children's Hospital (Hunter New

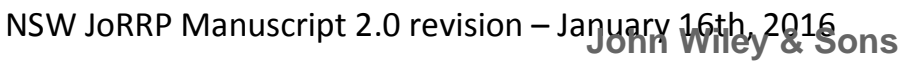

This article is protected by copyright. All rights reserved. 
England Health) and Sydney Children's Hospital at Randwick. Potential cases of RRP were identified by reviewing medical records of patients aged 0-16 years with hospital admissions between January 2000 and December 2009 containing the following ICD-10AM (Australian modification) codes and procedure codes, as retrieved by electronic medical record searches: D14.1 (benign neoplasm of larynx), D14.2 (benign neoplasm of trachea), D14.3 (benign neoplasm of bronchus), D14.4 (benign neoplasm of respiratory system), procedure code 521-4187000 (administration of other substance into vocal cord), 52341861 (microlaryngoscopy with removal of lesion by laser), 4186400 (microlaryngoscopy with removal of lesion), 4185200 (laryngoscopy with removal of lesion), or 9016100 (excision of other lesion of larynx). Clinicians who treat RRP at the hospitals were asked to independently identify cases of RRP they treated between 2000 and 2009.

$r$

For each record identified, we collected data regarding diagnosis, disease codes and procedure codes. Where a diagnosis of RRP was made, we extracted further information including treatment dates, length of stay, extent of laryngeal and tracheal involvement, complications, nature of surgical treatments and adjuvant treatments. Chi-squared tests were used to examine relationship between variables. Two sample t-tests were used to identify any sex-related differences in outcomes. We considered the time of active disease for each patient (person time in the denominator for rates) as the time between their first admission and their last. Where a patient had only one admission, we considered their person time as one month. We used Spearman's rank correlation to test the association between the average (and median) number of treatments per patient and the patient's year in treatment. Pearson's correlation was applied to test the association between age at diagnosis and the median time (months) between each patient's treatments. Following

NSW JoRRP Manuscript 2.0 revision - Jajuary 16 the 2215 Sons

This article is protected by copyright. All rights reserved. 
univariate analysis, logistic regression analysis was used to assess the relationship between complications and age at diagnosis and number of surgeries per patient (whilst adjusting for gender and follow-up time).

2) Estimated prevalence of RRP using national hospitalization data The sensitivity and specificity of D14.1 was calculated and the positive predictive value (PPV) and median number of hospitalizations per year applied to national hospital separations data for all hospitals (both public and private) in Australia between 2000/2001 and 2012/2013 obtained from the Australian Institute of Health and Welfare (AIHW) National Hospital Morbidity Database. Rates of hospital separation per 100,000 population per year were calculated using Australian Bureau of Statistics population estimates for the year of separation as the denominator. We examined males and females age 0 to 29 years, with primary focus the paediatric population $<15$. A chi-squared test was used to examine whether there was a significant change in the estimated average disease prevalence rate (estin (estimated based on hospitalisation rates) between the pre-vaccination (2000/1-2006/7) and post-vaccination (2007/8-2012/13) periods.

Ethical approval for the study across all sites was obtained from the Hunter New England Human Research Ethics Committee.

\section{Results}

\section{Identification of RRP cases}

Medical record search using diagnosis code D14.1 identified 30 patients treated for RRP across the three centres over the study period from 428 hospital admissions potentially

NSW JoRRP Manuscript 2.0 revision - Jajyary w6the 2815ons

This article is protected by copyright. All rights reserved. 
related to RRP. Detailed record review confirmed 420 of these admissions were related to treatment for RRP. Search by diagnosis code D14.2 and D14.3 or any procedure codes failed to identify any additional RRP-related cases or admissions. Treating clinicians did not identify any additional cases.

\section{Admissions in patients with RRP without primary code D14.1}

Two admissions for RRP had primary diagnosis code of D14.2 and secondary diagnosis code of D14.1. Medical record search by D14.1 did not capture ten RRP-related admissions identified on medical record review. These were usually due to a patient with previous RRP undergoing a diagnostic laryngoscopy which found no active disease.

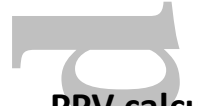

\section{PPV calculations and analysis}

The diagnosis code D14.1 (benign neoplasm of the larynx) was highly sensitive (97.7\%) for RRP admissions with a high positive predictive value of $98.1 \%$. Other diseases coded using D14.1 were laryngeal neurofibroma, cystic lymphangioma and supraglottic paraganglioma.

There were 2,808 hospital separations nationally between $2000 / 01$ and $2012 / 13$ in persons aged 0-29 years coded with D14.1 (benign neoplasm of larynx) (average annual rate 2.5 per 100,000 population). Of these 1,583 were in children aged under 15 (rate 2.97 per 100,000 ).

The average length of stay was 1.2 days in 1-4 year olds and 1.1 days for 5-14 year olds. Average separation rates by age and sex are presented in Table 1. Rates peaked in the 5-9 and $25-29$ year old age groups at 4.0 and 3.6 per 100,000 respectively.

NSW JoRRP Manuscript 2.0 revision - Jajuary 16 the 2 2 1 Sons

This article is protected by copyright. All rights reserved. 
When we applied the PPV of $98.1 \%$ for ICD code D14.1, and a median hospitalisation rate per year for RRP cases of 3.69 (obtained from clinical data review as below), we obtained the national prevalence rate estimates for juvenile onset RRP depicted in Figure 1. For the period $2000-2013$, the estimated disease prevalence rate was 0.81 per 100,000 in children aged under 15 and was highest in children aged 5-9 years at 1.1 per 100,000. The average prevalence rate did not significantly differ between the pre- (2000/1-2006/7) and postvaccine $(2007 / 8-2012 / 13)$ periods $(0.90$ vs 0.79 per $100,000, p=0.35)$. The greatest relative decline (45\%) occurred in the $0-4$ year age group but was not statistically significantly different (1.0 vs 0.56 per $100,000, p=0.18)$.
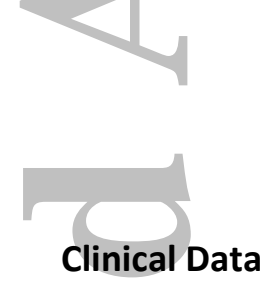

The 30 patients identified gives a prevalence rate in NSW of 2.0 per 100,000 population $0-16$ years assuming all active RRP cases attended tertiary centres. A slight majority (57\%) were female, with median age at diagnosis 36 months (range 6 months - 14.5 years, SD = 35 months). There was no significant difference in mean age at diagnosis between males (44.6 months) and females ( 47.8 months) ( $p=0.8)$. Distribution of cases by age at diagnosis is shown in Figure 2.

There were 375 RRP-related admissions identified in the record reviews (excluding emergency department or outpatient clinic visits), (mean 3.69 admissions per patient per year, and median 3.59.) Of these, 369 (98.4\%) involved administration of a general anaesthetic for diagnostic microlaryngoscopy and 336 (89.6\%) involved surgical intervention at the time of microlaryngoscopy. The median length of stay was one day (mean 1.3 days,

NSW JoRRP Manuscript 2.0 revision - Jajuary 16 却 2 2 1 Sons

This article is protected by copyright. All rights reserved. 
range $1-35, S D=2.5$ ) consistent with many day only surgical cases. The total number of surgical treatments per patient over the study period ranged from 1 to 56 (mean $=11.2$, median $=6, S D=14.1$ ). Ten patients had received treatment prior to the study. The total number of surgical interventions per patient for RRP-related disease including admissions prior to the study period ranged from 1 to 65 (mean $=18.7$, median $=9, S D=20.6$ ). At least ten patients continued receiving treatment subsequent to study end.

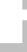
The median treatment duration from initial admission to final presentation over the study period was 36 months (mean $=40$ months, range $=1-118$ months). Eleven children ( $36.7 \%)$ had been treated for RRP for over five years and four children (13.3\%) for over ten years. Median number of surgical interventions per year was 3.11 (mean $=3.31, \mathrm{SD}=2.95)$, with no significant difference in mean number by sex (male 3.34 vs female 3.26 ; alpha $=0.05, p=$ 0.94). A significant negative association was found between the average (and median) number of treatments per patient and the patient's year in treatment (year one to year ten) using Spearman's rank correlation (mean treatments $r=-0.67, p=0.03$; median treatments $r=-$ $0.74 ; p=0.02$ ), suggesting that disease severity decreases over time. Age at diagnosis was found to have a moderate positive association with the median time between each patient's treatment (Pearson's correlation $=0.42 ; p=0.02$ ), suggesting those younger at diagnosis require more frequent procedures.

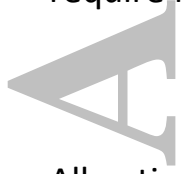

All patients had papillomatous lesions of the glottis during early periods of treatment. Anterior commissure involvement was common, being present in 24 cases (83\%) at some stage during treatment and in at least $70 \%$ of all microlaryngoscopy procedures across the study period. Distal spread into the trachea-bronchial tree was found at initial laryngoscopy

NSW JoRRP Manuscript 2.0 revision - Jajuary w6the 2815ons

This article is protected by copyright. All rights reserved. 
in two cases (6.7\%) however eight of 30 cases (26.7\%) were found to have distal lesions at some stage. Patients who experienced distal spread of disease had a significantly higher mean number of surgical treatments and admissions (two sample t-tests, mean procedures 5.32 vs $27.38 ; p<0.0001$ : mean admissions 6.41 vs $29.25 ; p<0.0001)$.

Surgical interventions in order of decreasing frequency included carbon dioxide laser resection (57.4\%), microdebrider resection (36\%), cold steel resection (5.6\%) and biopsy alone (0.9\%). The use of the microdebrider began in 2005 and in some cases replaced carbon dioxide laser resection as the primary method of ablation.

$<$

Adjuvant therapy was used in 11 of 30 patients (36.7\%), with interferon injections the most common adjuvant treatment. Three of nine patients experienced fever due to interferon.

One patient developed spastic diplegia during interferon treatment which is an uncommon but severe complication associated with interferon use in young children ${ }^{24,25}$. Five patients $(16.7 \%)$ received intralesional cidofovir injections $(5-10 \mathrm{mg} / \mathrm{mL})$ and three $(10 \%)$ received oral cimetidine (Table 2). 11 of 50 treatments employed cidofovir standalone with the remainder given in conjunction with an ablative procedure.

Treatment-related complications were recorded in 12 patients (40\%). No significant relationships were identified using logistic regression analysis (adjusting for follow up time and gender) between number of surgeries or age at diagnosis and the development of complications. Nine patients developed laryngeal webs or scar tissue as a result of treatment. All of these patients had been previously treated with $\mathrm{CO} 2$ laser resection. Six had an anterior laryngeal web, one of which was predominately supraglottic and required

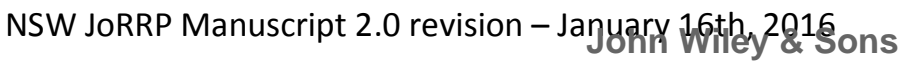

This article is protected by copyright. All rights reserved. 
multiple laser divisions in an attempt to improve the airway. The other three patients had predominately posterior glottic scar tissue in the interarytenoid region. One of these patients required tracheostomy for airway compromise due to posterior laryngeal stenosis. There was one patient death recorded. This patient presented under the age of three and developed halothane hepatitis ultimately requiring liver transplant. The patient displayed aggressive disease with distal respiratory spread requiring 60 RRP-related admissions before they passed away with chronic rejection of liver transplant.

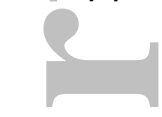

\section{Discussion}

Our previous pilot study ${ }^{23}$ established that most (73\%) ENT surgeons treating paediatric RRP in Australia do so in a tertiary paediatric hospital. The current study involves an extension of data collection to analyse paediatric RRP admissions over 10 years across all three tertiary paediatric hospitals in New South Wales - Australia's most populous state - representing almost a third of the Australian population of almost 24 million people. This study confirms that the ICD-10 code D14.1 (benign neoplasm of the larynx) is the primary diagnosis code used for coding admissions of patients with juvenile onset RRP and has a high positive predictive value (98.1\%). Applying this value, and the median number of hospitalisations per year of cases identified in our cohort (3.7), to national hospital separations data we estimated a prevalence rate of RRP in children under 15 years of age between 2000 and 2013 of 0.8 per 100,000, with a peak rate in 5 to 9 year olds of 1.1 per 100,000 . We did not find any significant decline in the number of RRP cases nationally estimated using hospital admissions data since the HPV vaccination program commenced. We did however note the largest relative decline (45\%) was in the $0-4$ year old age group, which would be expected if disease was being prevented through prevention of vertical transmission from mother to

NSW JoRRP Manuscript 2.0 revision - Jajuary 16 the 2215 Sons

This article is protected by copyright. All rights reserved. 
baby. The thirty cases of RRP identified in the medical record reviews had a median age of onset of 36 months and median treatment duration of 36 months although with considerable variability. Some $40 \%$ experienced complications.

som

Some significant limitations apply to our study. We assumed that the PPV we identified for coded hospital separations in NSW is consistent nationally, which may or may not be the case. Our inclusion of adults up to age 29 years in our hospital separation rates for code D14.1 should be interpreted with caution given that different pathologies may apply to this population, with adults more likely to undergo phonosurgical procedures for benign vocal fold pathology which may also be coded under D14.1. We also recognise that our estimate of RRP prevalence in NSW, will underestimate the total prevalence, given not all ENT surgeons treat RRP treatment at these centres. Whilst the national data includes private hospitals, these are not captured in our NSW estimates, suggesting that up to $25 \%$ of cases may have been missed. Under this assumption the prevalence estimate would rise from 2 per 100,000 in children 16 years and under, up to 2.5 per 100,000. This may be a worst case scenario given that previous studies have found that RRP may be associated with lower socio-economic status ${ }^{10,26}$, which may in Australia be associated with a greater likelihood of treatment in a public (government funded) hospital setting.

This study supports the significant morbidity associated with the diagnosis of RRP in a child. The chronic relapsing nature of RRP, and associated significant morbidity and effects upon quality of life ${ }^{1}$, as well as the lack of curative surgical or medical treatments, support the role of primary prevention of this condition.

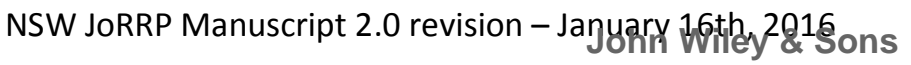

This article is protected by copyright. All rights reserved. 
In the Australian setting, with high uptake of quadrivalent HPV vaccine and declining genital warts and HPV6 and $11^{20-22}$, primary prevention through maternal vaccination is probably already occurring. Young women now have extremely low incidence of genital warts ${ }^{27}$ as do young men (who are also now being vaccinated in Australia), suggesting significant herd protection. Our data tentatively support the hypothesis that juvenile onset RRP incidence may be starting to decline, as do national surveillance data from the Australian Paediatric Surveillance Unit. These data, based on notifications of incident cases of juvenile onset RRP from paediatricians and paediatric ENT surgeons, have found year on year declines since surveillance commenced in late $2011^{28}$. Further monitoring of both hospitalisation data and notification data are required to confirm whether the disease is declining. In the interim we await further improvements in treatments, including the possibility of quadrivalent HPV vaccine having a therapeutic role, and are mindful that prevention may also be possible for infants of mothers with genital warts in pregnancy through administration of HPV vaccine to the mother by the transmission of maternal anti-HPV antibodies transplacentally. ${ }^{29}$

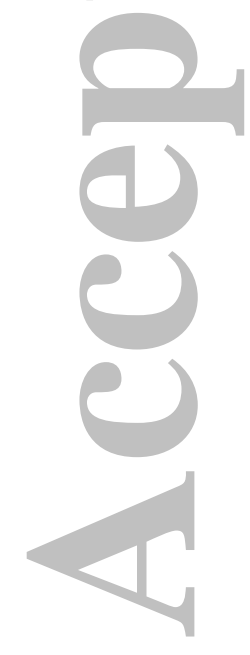

NSW JoRRP Manuscript 2.0 revision - Janyary 16 the 221 Sons

This article is protected by copyright. All rights reserved. 


\section{References}

1. Chadha NK, Allegro J, Barton M, Hawkes M, Harlock H, Campisi P. The quality of life and health utility burden of recurrent respiratory papillomatosis in children. Otolaryngol Head Neck Surg 2010;143:685-90.

2. Donne AJ, Hampson L, Homer JJ, Hampson IN. The role of HPV type in Recurrent Respiratory Papillomatosis. Int J Pediatr Otorhinolaryngol 2010;74:7-14.

3. Costa J, Howley PM, Bowling MC, Howard R, Bauer WC. Presence of human papilloma viral antigens in juvenile multiple laryngeal papilloma. Am J Clin Pathol 1981;75:194-7.

4. Braun L, Kashima H, Eggleston J, Shah K. Demonstration of papillomavirus antigen in paraffin sections of laryngeal papillomas. The Laryngoscope 1982;92:640-3.

5. Mounts $\mathrm{P}$, Shah KV, Kashima $\mathrm{H}$. Viral etiology of juvenile- and adult-onset squamous papilloma of the larynx. Proc Natl Acad Sci U S A 1982;79:5425-9.

6. Silverberg MJ, Thorsen P, Lindeberg H, Grant LA, Shah KV. Condyloma in pregnancy is

strongly predictive of juvenile-onset recurrent respiratory papillomatosis. Obstetrics and gynecology 2003;101:645-52.

7. Sedlacek TV, Lindheim S, Eder C, et al. Mechanism for human papillomavirus transmission at birth. Am J Obstet Gynecol 1989;161:55-9.

8. Fredericks BD, Balkin A, Daniel HW, Schonrock J, Ward B, Frazer IH. Transmission of human papillomaviruses from mother to child. Aust N Z J Obstet Gynaecol 1993;33:30-2.

9. Bonagura VR, Hatam LJ, Rosenthal DW, et al. Recurrent respiratory papillomatosis: a complex defect in immune responsiveness to human papillomavirus-6 and -11. Apmis 2010;118:45570.

10. Marsico M, Mehta V, Chastek B, Liaw KL, Derkay C. Estimating the incidence and prevalence of juvenile-onset recurrent respiratory papillomatosis in publicly and privately insured claims databases in the United States. Sexually transmitted diseases 2014;41:300-5.

11. Hawkes $M$, Campisi $P$, Zafar R, et al. Time course of juvenile onset recurrent respiratory papillomatosis caused by human papillomavirus. The Pediatric infectious disease journal 2008;27:149-54.

$12 . \quad$ Ongkasuwan J, Friedman EM. Juvenile recurrent respiratory papilloma: variable intersurgical intervals. The Laryngoscope 2012;122:2844-9.

13. Schiller JT, Castellsague X, Garland SM. A review of clinical trials of human papillomavirus prophylactic vaccines. Vaccine 2012;30 Suppl 5:F123-38.

14. Young DL, Moore MW, Halstead LA. The Use of the Quadrivalent Human Papillomavirus Vaccine (Gardasil) as Adjuvant Therapy in the Treatment of Recurrent Respiratory Papilloma. Journal of voice : official journal of the Voice Foundation 2015.

15. Meszner Z, Jankovics I, Nagy A, Gerlinger I, Katona G. Recurrent laryngeal papillomatosis with oesophageal involvement in a 2 year old boy: successful treatment with the quadrivalent human papillomatosis vaccine. International journal of pediatric otorhinolaryngology 2015;79:262-6. 16. Chirila M, Bolboaca SD. Clinical efficiency of quadrivalent HPV (types 6/11/16/18) vaccine in patients with recurrent respiratory papillomatosis. European archives of oto-rhino-laryngology : official journal of the European Federation of Oto-Rhino-Laryngological Societies 2014;271:1135-42. 17. Hocevar-Boltezar I, Maticic M, Sereg-Bahar M, et al. Human papilloma virus vaccination in patients with an aggressive course of recurrent respiratory papillomatosis. European archives of otorhino-laryngology : official journal of the European Federation of Oto-Rhino-Laryngological Societies 2014;271:3255-62.

NSW JoRRP Manuscript 2.0 revision - Jajyary 16th 2815 2 Sons

This article is protected by copyright. All rights reserved. 
18. Brotherton JM, Liu B, Donovan B, Kaldor JM, Saville M. Human papillomavirus (HPV) vaccination coverage in young Australian women is higher than previously estimated: Independent estimates from a nationally representative mobile phone survey. Vaccine 2014;32:592-7.

19. Brotherton JM, Murray SL, Hall MA, et al. Human papillomavirus vaccine coverage among female Australian adolescents: success of the school-based approach. The Medical journal of Australia 2013;199:614-7.

20. Tabrizi SN, Brotherton JM, Kaldor JM, et al. Assessment of herd immunity and crossprotection after a human papillomavirus vaccination programme in Australia: a repeat crosssectional study. The Lancet infectious diseases 2014;14:958-66.

21. Osborne SL, Tabrizi SN, Brotherton JM, et al. Assessing genital human papillomavirus genoprevalence in young Australian women following the introduction of a national vaccination program. Vaccine 2015;33:201-8.

22. Ali H, Donovan B, Wand H, et al. Genital warts in young Australians five years into national human papillomavirus vaccination programme: national surveillance data. BMJ (Clinical research ed 2013;346:f2032.

23. Novakovic D, Cheng AT, Cope DH, Brotherton JM. Estimating the prevalence of and treatment patterns for juvenile onset recurrent respiratory papillomatosis in Australia prevaccination: a pilot study. Sexual health 2010;7:253-61.

24. Barlow CF, Priebe CJ, Mulliken JB, et al. Spastic diplegia as a complication of interferon Alfa2a treatment of hemangiomas of infancy. The Journal of pediatrics 1998;132:527-30.

25. Michaud AP, Bauman NM, Burke DK, Manaligod JM, Smith RJ. Spastic diplegia and other motor disturbances in infants receiving interferon-alpha. The Laryngoscope 2004;114:1231-6.

26. Larson DA, Derkay CS. Epidemiology of recurrent respiratory papillomatosis. Apmis 2010;118:450-4.

27. Chow EP, Fehler G, Chen MY, et al. Testing commercial sex workers for sexually transmitted infections in Victoria, Australia: an evaluation of the impact of reducing the frequency of testing. PloS one 2014;9:e103081.

28. Deverell M, Zurynski YA, Elliott EJ. Australian Paediatric Surveillance Unit annual report, 2013. Communicable diseases intelligence quarterly report 2014;38:E343-2.

29. Matys K, Mallary S, Bautista O, et al. Mother-infant transfer of anti-human papillomavirus (HPV) antibodies following vaccination with the quadrivalent HPV (type 6/11/16/18) virus-like particle vaccine. Clin Vaccine Immunol 2012;19:881-5.

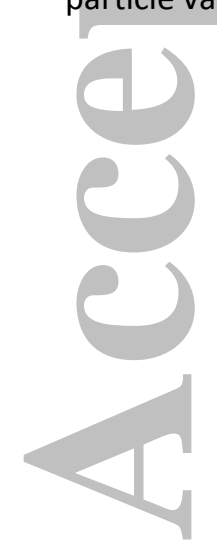

NSW JoRRP Manuscript 2.0 revision - Jajyary 16 the 2815 ons

This article is protected by copyright. All rights reserved. 
Figure Legends:

Figure 1 - Estimated RRP prevalence by age group and year for children aged under 15 years,

Australia 2000/01 to 2012/13

Figure 2 - Age distribution of 30 cases of juvenile onset RRP in hospitalised cases in NSW, Australia, by age at diagnosis.

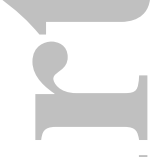

\section{Table Legends:}

Table 1 - Average annual hospital separation rates per 100,000 population by age and sex with principal diagnosis code D14.1 Benign neoplasm of larynx, 2000/01 to 2012/13. Source: AIHW National Hospital Morbidity Database

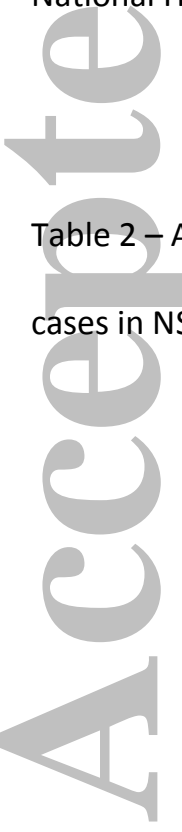

NSW JoRRP Manuscript 2.0 revision - Jajuary 16th 2815ons

This article is protected by copyright. All rights reserved. 


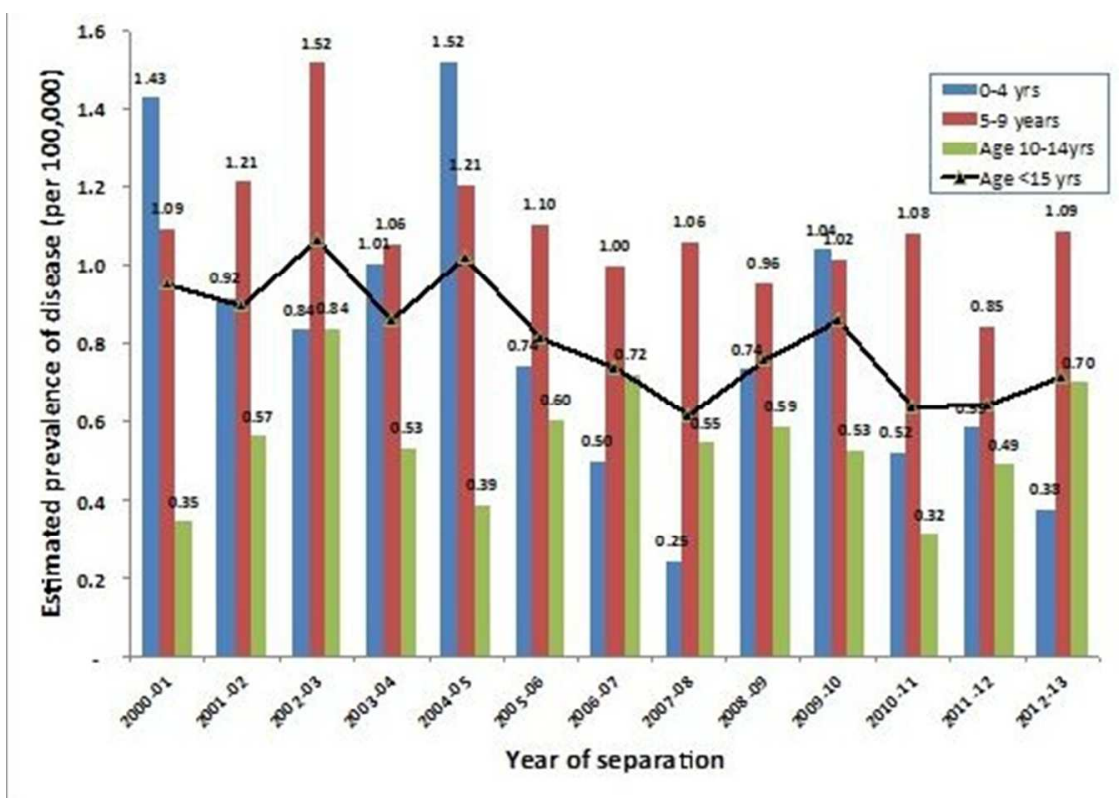

Estimated RRP prevalence by age group and year for children aged under 15 years, Australia 2000/01 to 2012/13

$158 \times 95 \mathrm{~mm}(96 \times 96$ DPI $)$

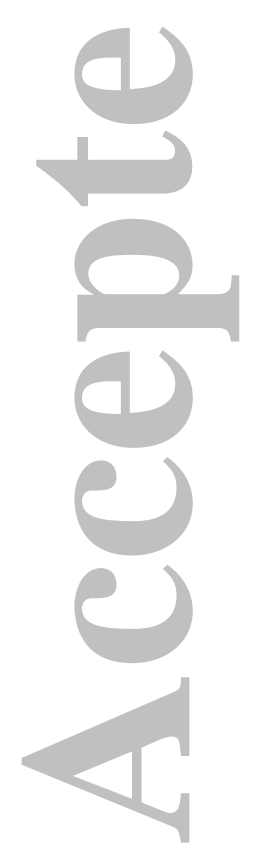

John Wiley \& Sons

This article is protected by copyright. All rights reserved. 


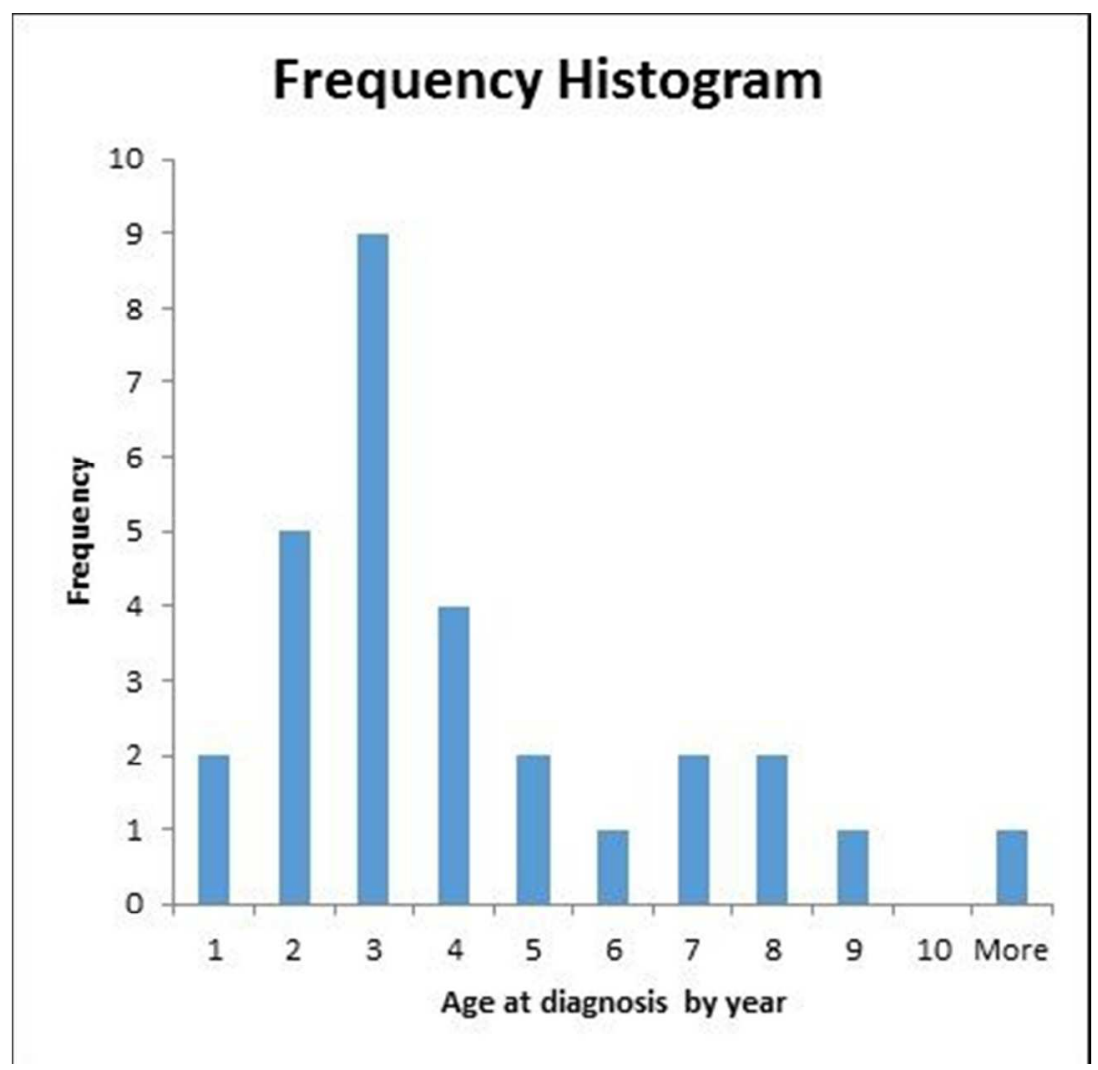

Age distribution of 30 cases of juvenile onset RRP in hospitalised cases in NSW, Australia, by age at diagnosis.

$109 \times 106 \mathrm{~mm}(96 \times 96 \mathrm{DPI})$

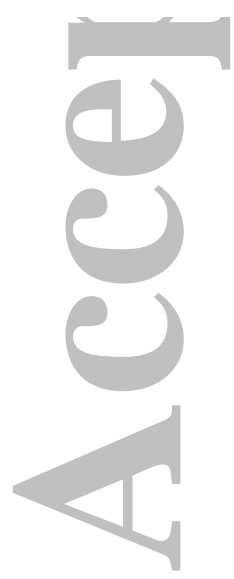

John Wiley \& Sons

This article is protected by copyright. All rights reserved. 
Table 1: Average annual hospital separation rates per 100,000 population by age and sex with principal diagnosis code D14.1 Benign neoplasm of larynx, 2000/01 to 2012/13. Source: AlHW National Hospital Morbidity Database

\begin{tabular}{|l|c|c|c|}
\hline $\begin{array}{l}\text { Age group } \\
\text { (years) }\end{array}$ & Male & Female & All \\
\hline $\mathbf{0 - 4}$ & 3.21 & 2.53 & 2.88 \\
\hline $\mathbf{5 - 9}$ & 4.21 & 3.84 & 4.03 \\
\hline $\mathbf{1 0 - 1 4}$ & 1.89 & 2.18 & 2.03 \\
\hline $\mathbf{1 5 - 1 9}$ & 0.79 & 0.84 & 0.81 \\
\hline $\mathbf{2 0 - 2 4}$ & 2.89 & 1.04 & 1.98 \\
\hline $\mathbf{2 5 - 2 9}$ & 5.57 & 1.55 & 3.58 \\
\hline All $\mathbf{0 - 2 9}$ years & 3.10 & 1.96 & 2.55 \\
\hline
\end{tabular}
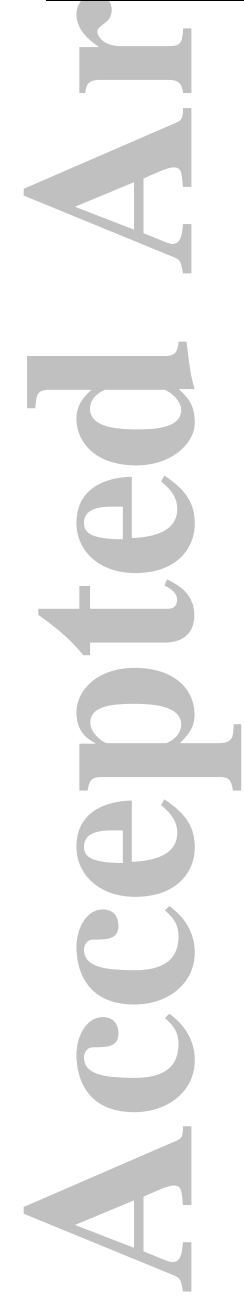
Table $\mathbf{2}$ - Adjuvant treatments given for RRP treatment among $\mathbf{3 0}$ cases of juvenile onset RRP in hospitalised cases in NSW, Australia

\begin{tabular}{|l|c|c|}
\hline Adjuvant Treatment given & $\begin{array}{l}\text { Number of } \\
\text { patients }\end{array}$ & \% of patients \\
\hline Interferon injections alone & 3 & 10 \\
Intralesional cidofovir alone & 1 & 3 \\
Oral cimetidine alone & 1 & 3 \\
Cidofovir + Interferon & 4 & 13 \\
Cimetidine + interferon & 2 & 7 \\
\hline Total & 11 & $37 \%$ \\
\hline
\end{tabular}
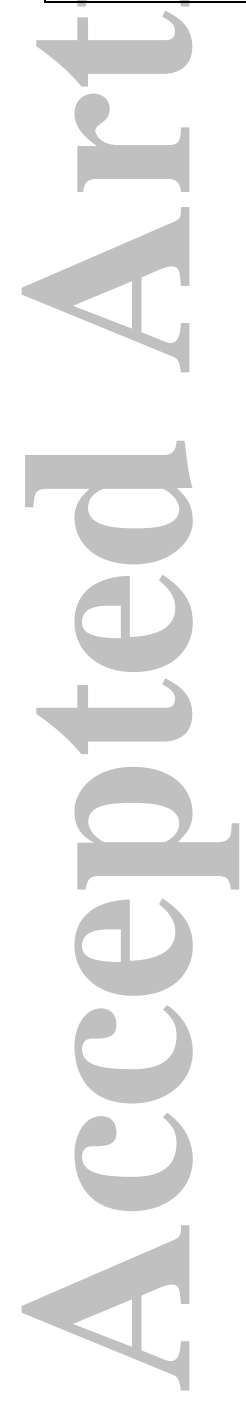

John Wiley \& Sons

This article is protected by copyright. All rights reserved. 


\section{University Library}

\section{- M M N E R VA A gateway to Melbourne's research publications}

Minerva Access is the Institutional Repository of The University of Melbourne

\section{Author/s:}

Novakovic, D;Cheng, ATL;Baguley, K;Walker, P;Harrison, H;Soma, M;Malloy, M;Brotherton, $\mathrm{JML}$

Title:

Juvenile recurrent respiratory papillomatosis: 10-year audit and Australian prevalence estimates

Date:

2016-12-01

Citation:

Novakovic, D., Cheng, A. T. L., Baguley, K., Walker, P., Harrison, H., Soma, M., Malloy, M. \& Brotherton, J. M. L. (2016). Juvenile recurrent respiratory papillomatosis: 10-year audit and Australian prevalence estimates. LARYNGOSCOPE, 126 (12), pp.2827-2832. https:// doi.org/10.1002/lary.26005.

Persistent Link:

http://hdl.handle.net/11343/291171 